\title{
Transanal Endorectal Pull-Through Procedure for patients with Hirschsprung`s Disease: A prospective study
}

\author{
Bilal H. Abdul-Ghafoor* \\ Ali F. Abdullah** \\ Makke A. F.Al-Amery*
}

\author{
FICMS Ped.Surg. \\ FICMS Ped.Surg. \\ FICMS Ped.
}

$J$ Fac Med Baghdad 2015 ; Vol.57, No.4 Received Apri.2015 Accepted Sept..2015

Back ground: Hirschsprung`s disease is a common problem among pediatric population, many procedures had been implemented in the treatment with different results. In the last decades one stage transanal endorectal pullthrough (TEPT) had come into the stage as a minimal invasive choice for such condition with good results.

Objectives: To evaluate the feasibility and safety of TEPT procedure among pediatrics in a tertiary pediatric surgery center in Iraq.

Patients and Methods: A prospective study was conducted on 11 patients with Hirschsprung's disease, attending Central Teaching Hospital of Pediatrics for the period from March 2007 till August 2014. Their ages were ranging from 1 month - 12 years. All cases had diverting colostomy and leveling biopsy. The aganglionic segment was confined to the rectum and rectosigmoid junction. TEPT was done to all cases with closure of colostomy 6-8 weeks after pullthrough. The patients were followed up for a period of 6 months- 4 years.

Results: The study was conducted on 11 patients with a mean age of ( $33.7 \pm 43.4$ months); the male to female ratio was 9:2. Regarding the level of aganglionosis, it was confined to the rectum in 4 cases, while it reached the rectosigmoid junction in 7 cases. The mean operating time was (115.4 \pm 23.5 minutes), and the mean volume of blood loss was $(37.3 \pm 17.6 \mathrm{ml})$. The average length of resected aganglionic segment was $(13.9 \mathrm{~cm})$. There is no conversion to laparotomy in any case. Complications developed in two cases one with perianal excoriation and the other develop postoperative enterocolitis.

Conclusion: Transanal Endorectal Pull-Through operation for Hirschsprung's disease is feasible and safe, and it can be performed successfully in all ages of children with good results avoiding transabdominal exploration.

Key words : Hirschsprung's disease, transanal endorectal pullthrough, aganglionosis.

Introduction:

Hirschsprung's disease (HSD) is the most common cause of intestinal obstruction in newborns (1). Colostomy in the neonatal period followed by a later pullthrough procedure was the standard treatment for the disease. Nowadays pediatric surgeons perform a primary pullthrough procedure in the neonatal period without the need for a preliminary colostomy (2). One stage entirely transanal endorectal pullthrough (TEPT) represents the revolution in minimally invasive surgery in Hirschsprung`s disease since De la Torre-Mondragon and Ortega-Salgado describe in 1998(3).The results of the TEPT approach in small infants appear to be at least as favorable as those in which a staged procedure with a colostomy was used(4). In TEPT approach there is a significant shortening of hospital stay (less cost), avoidance of colostomy and its complications

*Central Teaching Hospital of Pediatrics.

Email: bilalhamid2001@yahoo.com

**Dept of Surgery, ,College of medicine University of AlMustansiriyah, Central Teaching Hospital of Pediatrics. with comparable or better results without increased risk of complications than multistaged procedures(5). For above reasons TEPT gained popularity and widely used by pediatric surgery centers. The aim of this study was to evaluate the feasibility and safety of TEPT procedure among pediatrics in a tertiary pediatric surgery center in Iraq.

\section{Patients and Methods:}

A prospective study was conducted on 11 patients with Hirschsprung's disease, attending Central Teaching Hospital of Pediatrics for the period from March 2007 till August 2014. Their ages were ranging from 1 month - 12 years. All cases had HSD confirmed by rectal or colonic biopsy with barium enema. Double barrel colostomy and leveling biopsy were done to all cases. The aganglionic segment was confined to the rectum and rectosigmoid junction. The signs and symptoms of presentation were ranging from delayed passage of meconium, chronic constipation to complete intestinal obstruction. The criterion of exclusion was any patient with a long segment 
of aganglionosis. All cases receive Ceftriaxone $(50-75 \mathrm{mg} /$ $\mathrm{kg}$ ) and Metronidazole $(35-50 \mathrm{mg} / \mathrm{kg}$ ) one day before surgery. Bowel preparation done by saline wash and irrigation (through mucous fistula and the anus) twice daily for two days before surgery and intraoperatively in addition to diet modification during this period for older patients. TEPT was done to all cases as described below. Colostomy closure was done 6-8 weeks after TEPT. Then after, the patients were followed up for 6 months to 4 years.

\section{Surgical technique:}

After placement of intravenous line, induction of general anaesthesia with endotracheal intubation was done. The patient was placed in a lithotomy position with the pelvis slightly elevated at the end of operating table. The abdomen and perineum were prepared in the standard fashion. A urinary catheter was inserted. A circumferential row of 4-0 silk stay sutures were inserted approximately 0.5 to $1 \mathrm{~cm}$ above the dentate line. Submucosal injection of diluted epinephrine with saline was commenced. The rectal mucosa was incised just distal to the traction sutures and lifted circumferentially using fine diathermy needle to develop the submucosal plane. Once the submucosal plane was established, the dissection was easily continued proximally using blunt dissection and cauterization of submucosal infiltrating vessels. The dissection continued proximally until reaching $3-5 \mathrm{~cm}$ from the dentate line. Four stay sutures were inserted to control the upper end of muscular cuff, which was incised circumferentially allowing exposure of the full-thickness sigmoid colon. Mobilization of the colon was continued as proximal to the grossly obvious or histologically confirmed transition zone as possible by dividing the rectosigmoid vessels after cauterizing them. After resection of the aganglionic segment, the normally innervated bowel was pulled through the shortened muscular cuff $(2-3 \mathrm{~cm})$ and anastomosed to the remaining mucosa above the dentate line using 4-0 slowly absorbable suture material. Anal dilatation started two weeks postoperatively.

\section{Results:}

The study was conducted on 11 patients with a mean age of (33.7 \pm 43.4 months); the male to female ratio was 9:2. Regarding the level of aganglionosis, it was confined to the rectum in 4 cases $(36.4 \%)$, while it reached the rectosigmoid junction in 7 cases (63.6\%). Operative details include an operating time ranging from (80-160 minutes) with a mean of (115.4 \pm 23.5 minutes), the amount of blood loss was ranging from $(20-80 \mathrm{ml})$ with a mean of $(37.3 \pm 17.6 \mathrm{ml})$, with no patient required intraoperative blood transfusion. The average length of resected aganglionic segment was $(13.9 \mathrm{~cm})$ ranging from $(9-25 \mathrm{~cm})$. Bowel motion started one day after surgery, while oral feeding initiated 3 days after operation with a mean hospital stay of ( $6.5 \pm 1.5$ days) ranging from ( $4-9$ days $)$ as illustrated in table 1. There is no conversion to laparotomy in any case. One patient developed perianal skin excoriation and responded to outpatient medical treatment, while another case develop grad 2 enterocolitis required admission to hospital and conservative therapy including colonic decompression, rehydration, and antibiotic coverage.

Table -1- Operative results and hospital stay

\begin{tabular}{ccc}
\hline & Range & Mean \\
\hline Age (months) & $1-144$ & $33.73 \pm 43.42$ \\
\hline Length of resected bowel (cm) & $9-25$ & 13.9 (average) \\
\hline Blood loss (ml) & $20-80$ & $37.36 \pm 17.64$ \\
\hline Operative time (minutes) & $\mathbf{8 0 - 1 6 0}$ & $115.45 \pm 23.5$ \\
\hline Hospital stay (days) & $4-9$ & $6.5 \pm 1.5$ \\
\hline
\end{tabular}

\section{Discussion:}

The conventional three stages procedure of HD by Swenson, Duhamel, and Soave had been substituted in the last two decades by the one stage TEPT and starts to gain popularity among pediatric surgeons due to its feasibility and less complication with results equal if not better than the traditional three stage procedures(6).In our study TEPT was carried on 11 patients, their ages were ranging from 1 month to 12 years; with a mean of (33.7 \pm 43.4 months), which reflects a wide range of ages at the time of pullthrough which refers to the feasibility of TEPT during and beyond the neonatal period, a fact that was documented by other studies done by Langer et al(7), and Bahatial et al(8). In the present series the male: female ratio was 4.5:1 which is differs from Ortiz-Rubio et al(9) who described a male: female ratio of $1.8: 1$ but it agrees with the general concept and Langer et al(7) who described a ratio of $4: 1$. In this study all the patients had colostomy and leveling biopsy due to unavailability of frozen section at the time of the study to document the level of resection of the aganglionic segment during TEPT . TEPT is usually done alone when the aganglionic segment was not extending beyond the rectosigmoid region; otherwise assisted laparoscopy or laparotomy is required to mobilize the colon(10). In this series all the selected patients had aganglionic segment either in the rectum; 4 patients $(36.4 \%)$, or reaching the rectosigmoid junction; 7 patients $(63.6 \%)$ that is why neither laparoscopy nor laparotomy were needed. The first description of TEPT was associated with a long muscular cuff that is reaching the peritoneal reflection; such a long cuff was blamed for the constipation, stricture and enterocolitis. Using a short muscular cuff of less than $2 \mathrm{~cm}$ had been advised by some authors to decrease such postoperative complications $(11,12)$ and we use such technique in our patients. Anal dilatation was started two weeks postoperatively and continued for 3 months in a frequency 
of once daily. The average length of resected segment was 13.9 $\mathrm{cm}$ which is comparable to other studies as expressed in table 2. The operating time (excluding induction of anaesthesia and recovery) was ranging from 80-160 minutes, with a mean of (115.4 \pm 23.5 minutes) it was less in neonates and infants while longer in older patients which was attributed to the fact that mucosal dissection in neonate is easier than in older children due to inflamed mucosa, thick mesentery, and longstanding dilated colon $(8,13,14)$.Intraoperative blood loss was ranging from $20-80 \mathrm{ml}$ with a mean of $(37.3 \pm 17.6 \mathrm{ml})$ with no patient required blood transfusion during the procedure, this figure was comparable to other studies but it looks larger than Hassan (12) study who described a mean intraoperative blood loss of $20 \pm 2.4 \mathrm{ml}$ (table 2); which could be attributed to the same factors described above since his study included only neonatal patients. Regarding complications in our study we had one patient who aged 2 years developed perianal skin excoriation after 2 weeks from the closure of colostomy and responded to outpatient medical treatment within 4 weeks. Enterocolitis is regarded as the main complication of HD patients before and after treatment. Literatures had described an incidence of postoperative enterocolitis to reach as high as $32-42 \%$ (15), in this paper we had only one patient who was 12 years old at the time of TEPT developed grade 2 enterocolitis 6 months from colostomy closure, which necessitated his admission to hospital with bowel rest, colonic decompression, rehydration and antibiotic coverage and remain there for 10 days then discharged well with no another attack during the follow up period. No patient in this study needed reoperation. This low incidence of complications in our study could be due to the fact that all patients already had a colostomy which prevented the development of a dilated colon, in addition to shortening of the muscular cuff to $2 \mathrm{~cm}$ during pullthrough operation.(12) Constipation and incontinence were difficult to be assessed during the study as most of the patients were on diapers during the follow up period with only 2 patients who were aged 12 and 6 years were neither constipation nor incontinence were reported during this period.

Table -2- Results comparison with other studies.

\begin{tabular}{|c|c|c|c|c|c|c|c|c|c|}
\hline \multirow{2}{*}{$\begin{array}{l}\text { Parameters } \\
\text { Studies }\end{array}$} & \multirow{2}{*}{ Age (mean) } & \multirow{2}{*}{$\begin{array}{l}\text { Gender } \\
\text { (M:F) }\end{array}$} & \multirow{2}{*}{$\begin{array}{c}\text { Length of } \\
\text { resected } \\
\text { bowel (mean) }\end{array}$} & \multicolumn{2}{|c|}{$\begin{array}{c}\text { Level of aganglionic } \\
\text { segment }\end{array}$} & \multirow{2}{*}{$\begin{array}{l}\text { Blood loss } \\
\text { (mean) }\end{array}$} & \multirow{2}{*}{$\begin{array}{l}\text { Operative } \\
\text { time } \\
\text { (mean) }\end{array}$} & \multirow{2}{*}{$\begin{array}{c}\text { Perianal } \\
\text { excoriation }\end{array}$} & \multirow{2}{*}{ Enterocolitis } \\
\hline & & & & rectum & rectosigmoid & & & & \\
\hline $\begin{array}{l}\text { Present study } \\
\qquad(n=11)\end{array}$ & $\begin{array}{c}1-144 \text { month } \\
(33.73 \pm 43.42)\end{array}$ & $9: 2$ & $\begin{array}{c}9-25 \mathrm{~cm} \\
(13.91 \pm 5.02)\end{array}$ & 4 & 7 & $\begin{array}{c}20-80 \mathrm{ml} \\
(37.36 \pm 17.64)\end{array}$ & $\begin{array}{l}80-160 \min * * \\
(115.45 \pm 23.5)\end{array}$ & 1 & 1 \\
\hline $\begin{array}{l}\text { Waheeb }(16) \\
\quad(n=14)\end{array}$ & $\begin{array}{c}(25 \pm 0.61 \\
\text { month })\end{array}$ & $11: 3$ & $(24.2 \pm 9.3 \mathrm{~cm})$ & 6 & $\begin{array}{c}4(\text { sigmoid }=3, \\
\text { Descending } \\
\text { colon }=1)\end{array}$ & $(12.4 \pm 7.1) \mathrm{ml}$ & $\begin{array}{l}(43.5 \pm 2.2) \\
\min * *\end{array}$ & 4 & $\mathbf{0}$ \\
\hline $\operatorname{Ali}(14)(n=28)$ & 5-30 days & $3: 1$ & $14-35 \mathrm{~cm}$ & 2 & $\begin{array}{c}13 \\
\text { (descending } \\
\text { colon=4, splenic } \\
\text { flexure=2) }\end{array}$ & $\mathbf{N R}^{*}$ & $(90 \pm 18) \mathrm{min}^{* *}$ & 18 & 4 \\
\hline $\begin{array}{c}\operatorname{Hassan}(13) \\
(n=42)\end{array}$ & $\begin{array}{l}\text { 2week- } \\
\text { 2months }\end{array}$ & $9: 5$ & $\begin{array}{c}20.8 \mathrm{~cm} \\
(15-30)\end{array}$ & 11 & $\begin{array}{c}19 \\
(\text { sigmoid=12) }\end{array}$ & $\begin{array}{c}20 \mathrm{ml} \\
(15-30)\end{array}$ & $\begin{array}{c}75-100 \\
(80) \min ^{* *}\end{array}$ & 11 & 5 \\
\hline $\operatorname{Saleh}(17)(n=40)$ & $\begin{array}{l}\text { 6months- } \\
\text { 2years }\end{array}$ & NR* & $20-45 \mathrm{~cm}$ & 4 & $\begin{array}{c}30 \\
\text { (Mid sigmoid } \\
n=6)\end{array}$ & NR* & NR* & 10 & 8 \\
\hline $\begin{array}{l}\text { Langer(7) } \\
(\mathrm{n}=141)\end{array}$ & $\begin{array}{c}(145.9 \pm 81.1 \\
\text { days }) \\
1-4380 \text { days }\end{array}$ & $113: 28$ & NR* & NR* & NR* & $14.5 \pm 12.1 \mathrm{ml}$ & $\begin{array}{c}60-490 \\
(204 \pm 38.2) \\
\min * *\end{array}$ & 15 & 9 \\
\hline $\begin{array}{l}\text { Murugadas }(18) \\
\qquad(n=10)\end{array}$ & 19-32 days & $7: 3$ & NR* & $\mathbf{0}$ & 10 & NR* & 90 min **. & 3 & NR* \\
\hline
\end{tabular}

*NR= Not Reported

$* * \min =$ minute 


\section{Conclusions:}

Transanal Endorectal Pull-Through operation for Hirschsprung's disease is feasible and safe, and it can be performed successfully in all ages of children with good results avoiding transabdominal pullthrough procedures.

\section{Author's contributors:}

Ali F. Abdullah : specialist pediatric surgeon assists in most operations, share in data analysis and design , and follow up of patients.

Makke A. Faraj: shared in collecting data by referring patients from pediatric department, stabilizing them, following them postoperatively, interpretation of complications and revision of the results of treatment.

\section{References:}

1. Cilley RE, Statter MB, Hirschl RB : Definitive treatment of Hirschsprung's disease in newborn with a one-stage procedure. Surgery 115:551-556, 1994.

2. Georgeson KE, Fuenfer MM, Hardin WD: Primary laparoscopic pull-through for Hirschsprung's Disease in infant and children. J Pediatr Surg 1995,30:1017-1022.

3. De la Torre-Mondragon L, Ortega-Salgado JA: Transanal endorectal pull-through for Hirschsprung's disease. J Pediatr Surg 33:1283-1286, 1998.

4. Langer JC, Seifert M, Minkes RK: One-Stage Soave pullthrough for Hirschsprung's diseas: A comparison of the transanal and open approaches. J Pediatr Surg 35:820-822, 2000 .

5. Albanese CT, Jennings RW, Smith B, Bratton B : Perineal one-stage pull-through for Hirschsprung's disease. J Pediatr Surg 34:377-380, 1999.

6. Langer JC, Minkes RK, Mazziotti MV : Transanal one-stage Soave procedure for infants with Hirschsprung's disease. J Pediatr Surg 34:14,2000.

7. Langer JC et al . One stage Transanal Soave Pullthrough for Hirschsprung Disease: A Multicenter Experience with 141 children. Ann Surg. Oct.2003,238(4):569-576.

8. Bhatia, P., Joshi, R., Ramji, J., Bachani, M., \& Uttarwar, A. (2013). SingleStage TransanalPull-Throughfor Hirschsprung's Disease in Neonates: Our Early Experience. Journal Of Neonatal Surgery, 2(4), 39. Retrieved fromhttp://www. jneonatalsurg.com/ojs/index.php/jns/article/view/86/137

9. Ortiz-Rubio I, Maria PA, Christina G, Pernilla S, Einar A. Literature review of the outcome after one-stage Transanal Endorectal Pull-Through Procedure for Hirschsprung's Disease in Children. Surgical science,2013,4:258-262.

10. De La Torre L, Ortega A. Transanal versus open endorectal pull-through for Hirschsprung's disease. J Pediatr Surg. 2000, $35: 1630-1632$

11. Wester T, Rintala RJ. Early outcome of transanal endorectal pull-through with a short muscular cuff during the neonatal period. J Pediatr Surg. 2004; 39:157-60.

12. Elhalaby EA, Hashish A, Elbarbary MM et al. Transanal onestage endorectal pull-through for Hirschsprung's disease: A multicenter study. J Pediatr Surg 2004; 39: 345-51.

13. Hassan HS. One stage transanal endorectal pull-through procedure for Hirschsprung's disease in neonates. Ann Pediatr Surg. 2009; 5:21-26.

14. Ali KA. Transanal Endorectal pullthrough for Hirschsprung 's Disease During the First Month of Life. Ann Pediatr Surg. 2010; 6(2):81-88.

15. Hackam DJ, Filler RM, Pearl RH. Enterocolitis after the surgical treatment of Hirschsprung's disease: Risk factors and financial impact. J Pediatr Surg. 1998; 33:830-3.

16. Waheeb SM, Shehata MA. Pull-Through procedure for Hirschsprung 's Disease:Transanal or Transabdominal?A comparative study.EJS 2004;23(3):263-269.

17. Saleh AM, Hassan A, Wesam A, Amr A. Hirschsprung 's Disease: Early and Late Outcome after Correction by Transanal Pull-through. Ann Pediatr Surg. 2009; 5(1):27-30. 18. Murugadas $R$ et al. Neonatal Transanal Pull Through for Hirschsprung `s Disease. JIPS 2001; 6:69-71.

19. Iraqi virtual scientific library (IVSL): www.ivsl.org. 